\title{
Investigation of the Effects of Air-Conditioning System on the Temperature and Speed of Automobile Engine Using Paired T-Test and Regression Analysis
}

\author{
Olufemi Sylvester Bamisaye ${ }^{1 *}$, Anthony Yinka Oyerinde1, Ubong Akpan Essien² \\ ${ }^{1}$ Department of Production and Industrial Engineering, Federal University of Technology, Akure, Nigeria \\ ${ }^{2}$ Department of Material and Metallurgical Engineering, Federal University of Technology, Minna, Nigeria \\ Email: `bamisayesylvester1988@gmail.com, yinkusthony@gmail.com, essienubong4@gmail.com
}

How to cite this paper: Bamisaye, O.S., Oyerinde, A.Y. and Essien, U.A. (2019) Investigation of the Effects of AirConditioning System on the Temperature and Speed of Automobile Engine Using Paired T-Test and Regression Analysis. Open Access Library Journal, 6: e5090 https://doi.org/10.4236/oalib.1105090

Received: December 3, 2018

Accepted: January 7, 2019

Published: January 10, 2019

Copyright $\odot 2019$ by author(s) and Open Access Library Inc.

This work is licensed under the Creative Commons Attribution International License (CC BY 4.0).

http://creativecommons.org/licenses/by/4.0/

\begin{abstract}
This study investigated the effect of air-conditioning system on the temperature and speed of automobile engine before and after the air-conditioning system was put to use, while the vehicle was at static position. A 16-valve Nissan engine was used for this study, the engine was first run for 20 minutes before the data are collected. In the first case, the temperatures $\left({ }^{\circ} \mathrm{C}\right)$ of the engine were taken in the interval of 10 minutes before and after the air-conditioning system is run and in the second case, the speeds of the engine were taken under the same conditions. The research hypothesis was formulated for 20 observations to argue that neither temperature nor speed of the engine changes when the air-conditioning system is put on and Paired $\mathrm{t}$-Test statistics were used. The obtained result of $\mathrm{t}$-statistics analysis for temperature and speed were -4.0329 and -5.51832 respectively. These results when compared to their critical values at 5 percent significant level, $t$-Stat critical $_{\text {ind }}$ $<-1.73$ for temperature and speed, were discovered to be at the rejection region which indicates that the null hypothesis $\left(\mathrm{H}_{\mathrm{t} 0}\right.$ and $\left.\mathrm{H}_{\mathrm{s} 0}\right)$ in each case is rejected and accept that the air-conditioning system changes the temperature of the engine. Also, changes in speed requirements of the engine are not immediate and it could be as a result of an increase in fuel consumption due to more load on the engine. The regression correlation coefficients of 0.999996066 and 0.999653453 were obtained for the temperatures and speeds respectively with their $\mathrm{R}^{2}$ values, 0.999992132 and 0.999307027 . The coefficients in the analysis were used to formulate the regression equations; $\mathrm{T}_{2}=$ $135.640+1.025 \mathrm{t}+0.496 \mathrm{~T}_{1}$ and $\mathrm{N}_{2}=634.005+3.824 \mathrm{t}+0.270 \mathrm{~N}_{1}$ which can be used to forecast the temperatures and speeds of the engine during air-conditioning usage giving the initial parameters.
\end{abstract}




\section{Subject Areas}

Mechanical Engineering

\section{Keywords}

Paired t-Test, Automobile Air Conditioning, Regression, Temperature, Speed

\section{Introduction}

Automobile engineering is one of the main branches of engineering that deals with the various types of automobiles, their mechanism of transmission systems, cooling system, subsystems (such as air conditioning) and its applications. Almost all of the vehicle which is automobiles work on the fundamental of internal combustion processes and are called internal combustion engines (ICE). Therefore, the distinct types of fuels are burnt inside the cylinders at enhanced temperatures to get the transmission motion in the vehicles. Apart from the mechanisms that propel the wheels of the vehicles to get them into motion, it has also become equally important to maintain the comfortability in the vehicles while in motion or stationary [1]. People or passengers while in vehicles may feel uncomfortable due to excessive heat or polluted air as shown in Figure 1. In view of this, the use of air conditioning has become very important in the modern vehicle manufacturing to sustain the thermal comfort of passengers while reasonably quiet and also aid in defogging of vehicle windows so as to increase the active safety factor [2]. According to Daly [3], a prominent firm named Packard became the first automobile manufacturer to proffer ways of installing the air-conditioning unit for cars in 1939. The development of automobile air conditioning system since many years ago has left serious concerns on the minds of the vehicle owners, operators, and maintenance personnel as to know how much the effect it can have on their vehicles. The Heating, Ventilation and Air Conditioning system (HVAC) is a vital accessory which helps people to stay comfortable in the vehicle irrespective of the ambient (outside) conditions. However, since the A/C is powered by the same belt which operates the alternator, water pump, power steering pump, and other accessories, it has become important to examine its effects on the engine. Air-conditioning system pulls energy from the engine during operation and this is noticed as the engine's speed increases at idle when the compressor is running. Therefore, there is a need to investigate the popular question being raised on the effect of air-conditioning system on the internal combustion engines. The mode of working or the functions performed by the important components of automobile A/C systems are very much the same with the similar components in the conventional A/C systems that people use in their homes and offices as shown in Figure 2. The components such as an evaporator, compressor, condenser, thermal expansion valve and receiver which are common in the conventional $\mathrm{A} / \mathrm{C}$ systems are also found virtually in all automobile A/C systems (Figure 3). 


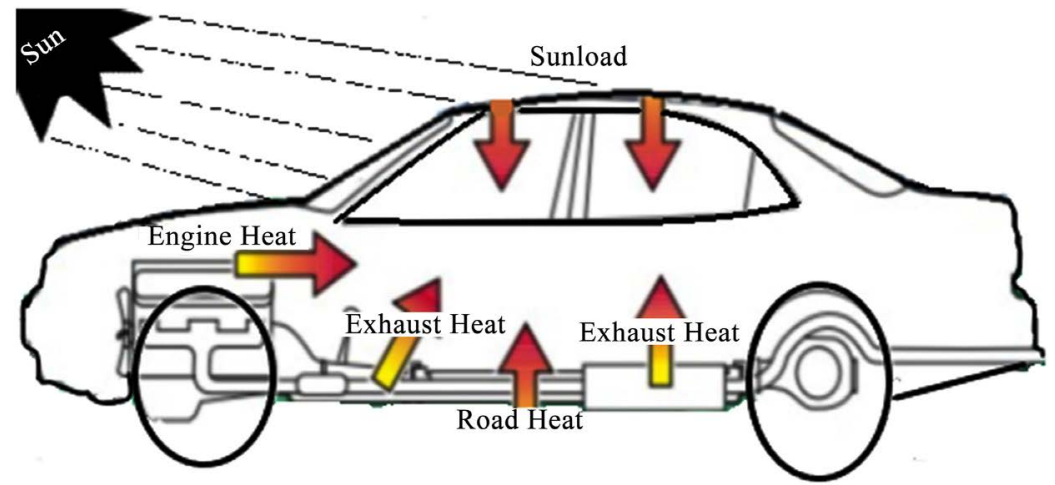

Figure 1. Mode of heat sources in the vehicle [9].

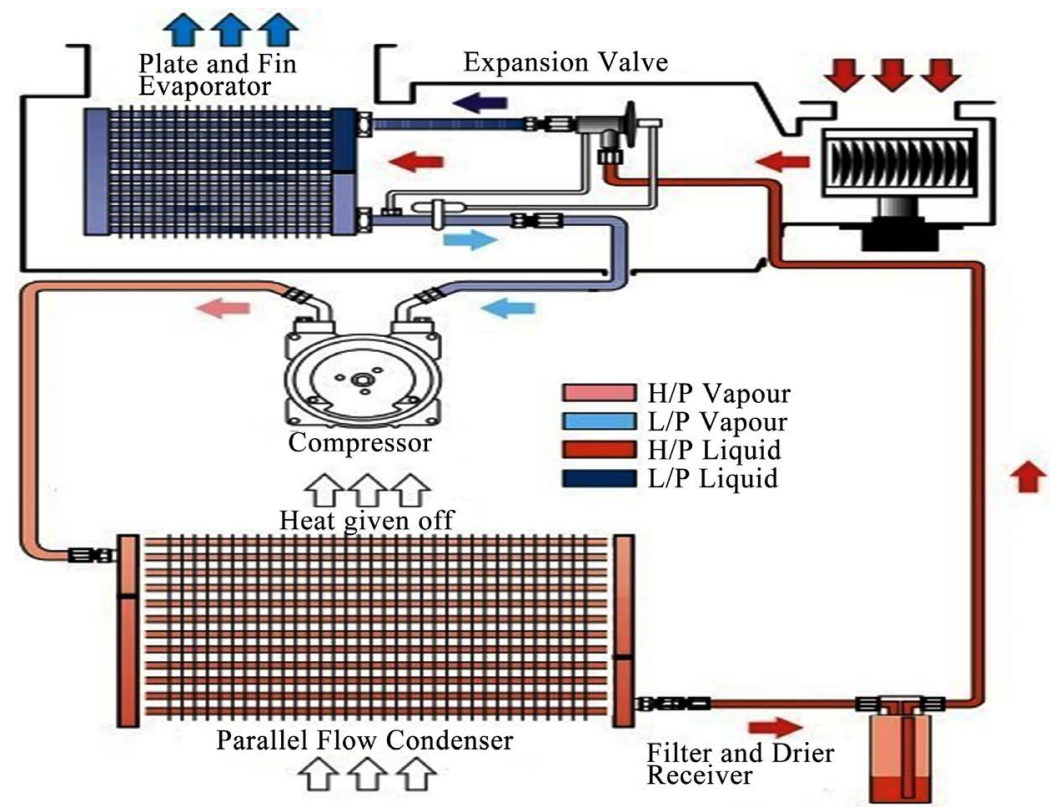

Figure 2. Schematic arrangement of components of the automobile air conditioning system [9].

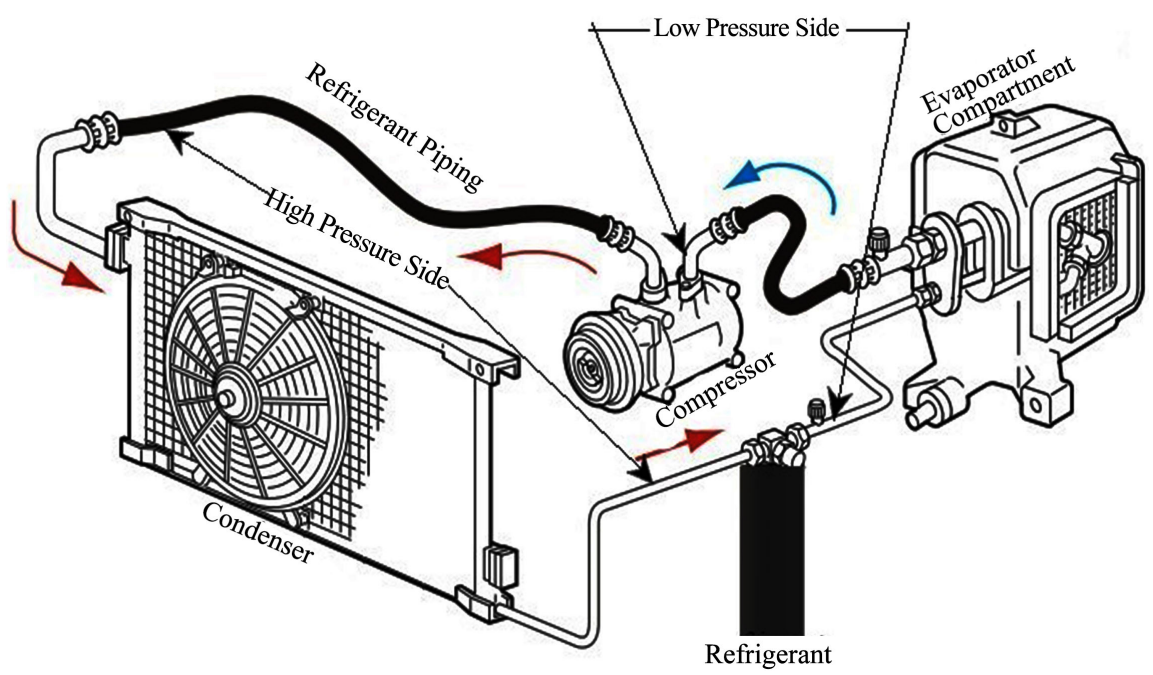

Figure 3. Shapes of some of the components of automobile air conditioning system [9]. 
Figure 3 shows the shapes of the common automobile A/C components. The diagram consists of the high pressure and low pressure sides which are similar to the A/C system used at homes, offices, halls and other A/C applications. The low pressure side consists of the suction piping to the inlet of the evaporator, the evaporating unit and the piping arrangement to the inlet of the compressor. The high pressure side consists of the piping arrangement from the exit of the compressor unit, the condenser unit and piping to the inlet of the throttle device. The mode of operation is in such a way that the refrigerant vapour at low temperature and pressure (in the evaporator) enters the "compressor" where it is compressed is entropically (constant entropy) and subsequently its temperature and pressure increase considerably. This vapour after leaving the compressor enters the "condenser" where it is condensed into high pressure liquid and is collected in a "receiver tank", from receiver tank it passes through the "expansion valve", here it is throttled down to a lower pressure and has a low temperature. After finding its way through expansion "valve" it finally passes on to "evaporator" where it extracts heat from the surroundings or circulating fluid being refrigerated and vapourises to low pressure vapour [4].

Javotkova and Pavelek [5] described the alternate trends in the field of automobile air conditioning, the study was focused on the refrigerant, ventilation, and types of control system installed in the A/C system for internal combustion engines. An assessment was conducted about the most widely used contemporary refrigeration system working with the refrigerant R134a and a promising transcritical refrigeration system employing refrigerant $\mathrm{CO}_{2}$ as its working medium. Meanwhile, the assessment did not reflect the effect of air-conditioning system on the internal combustion engines using any methods. Another study by Kiatsiriroat and Euakit [6], investigated and analyzed the coefficient of performance of an automotive air-conditioning system with R12/R124/R152a refrigerant mixture. Ratts and Brown [7] used experimental method to determine the automobile A/C system coefficient of performance, focusing on the interrelationships between the coefficient of performance, vehicle speed, and the compressor revolutions. Wang and $\mathrm{Gu}[8]$ performed an experimental analysis of an automotive air conditioning system with two-phase flow measurements. The obtained experimental results reveal there is a relationship in the coefficient of performance, evaporator cooling capacity, compressor power consumption, total mass flow rate, pressures, and temperatures in an automotive air conditioning system.

In another literature by ariazone automotive training handbook [9], the theory of heat, pressure, temperature, and refrigerants were discussed in relation to internal combustion engines. The internal combustion engines, air-conditioning system components, and servicing methodology were also addressed but the real effects of the $\mathrm{A} / \mathrm{C}$ on internal combustion engines were not discussed. In this study, the aim is to investigate statistically the effect of air conditioning systems on internal combustion engines through the set of design objectives, formulate the research hypotheses to investigate the effect of $\mathrm{A} / \mathrm{C}$ on the internal combus- 
tion engines using pair t-test at 5\% significant level for the data obtained from time, speed and temperature variations before and after A/C is run on the modeled engine, and finally determine the model relationship through equation generated between time, speed and temperature before and after $\mathrm{A} / \mathrm{C}$ is run on the modeled engine. Hence, three variables such as time (in minutes), speed and temperature of the engine were considered and their respective effects were investigated while the engine was running at a static position. The static position was considered because of a drop of engine speed usually notice while the vehicle $\mathrm{A} / \mathrm{C}$ is run at vehicle's static position.

\section{Material and Method}

\subsection{Equipment Specification}

The equipment used are:

1) digital multimeter (Voltcraft, AT-200) with K-Type thermocouple sensors. The range specifications were $20^{\circ} \mathrm{C}$ to $760^{\circ} \mathrm{C}$ and the accuracy of $\pm 3 \%$ for temperature measurement; and

2) digital laser photo tachometer, Hard shell ABS plastic digital non-contact with range 2.5 to 100,000 (RPM) for speed measurement. Calibrated in revolutions per minute (RPM) at the speed range of 600 to 4000 (RPM) and the accuracy of $\pm 2 \%$ Output of $\leq 1 \mathrm{MW}$; Mirror length of L50 by W25 mm overall size of L130 by W65 $\mathrm{mm}$ and Scan diameter of $20 \mathrm{~mm}$. Mirror length of L50 by W25 $\mathrm{mm}$.

\subsection{Experimental Set up}

\section{Temperature and Speed Measurements}

The temperature measurements were taken when the switch of the K-type thermo-sensors meter was set to the temperature position in degree celsius within the range of $20^{\circ} \mathrm{C}$ to $760^{\circ} \mathrm{C}$. The probes of the meter were connected into the sockets 6 and 7 and the readings of the temperatures were taken from the engine at an idle speed in the intervals of ten minutes. The same procedure was repeated when the A/C of the vehicle was on. To measure the speed, a reflective mark (a reflective tape) was created on the power belt that transmitted power from the engine to both alternator and compressor. The belt is used because it is running at the same speed as the engine. The beam of the laser tachometer was carefully aimed at the belt within the distance of $20 \mathrm{~mm}$ while rotating during when the engine is running, each time the reflective point passes the beam of the tachometer, some light is allowed back towards the tachometer, this light is picked up by the tachometer sensor while at the same time count the number of times the light is triggered in a given time to measure the speed of the engine. The same process was repeated when the A/C system was put on.

\subsection{Data Collection and Analysis}

The set of data for temperatures and speeds of the engine were collected at the 
condition when the $\mathrm{A} / \mathrm{C}$ was not running and later when running. The engine was first to run for some 20 minutes so that it can reach the required thermal condition. The temperatures of the engine were then taken and recorded in the interval of 10 minutes when the $\mathrm{A} / \mathrm{C}$ system was off, the $\mathrm{A} / \mathrm{C}$ system was later put on and the temperatures were measured and recorded again in the interval of 10 minutes. The same procedures were done for the measurement of the speeds of the engine with photo tachometer. The data collected were analyzed with paired t-test to compare the effect of the air-condition on the temperature and speed of the engine at a 5\% significance level using excel data analysis package. More analyses were done to also know the relationship between the variables considered and their effects on the engine over the period of time.

\subsection{Temperature Research Hypothesis}

The purpose of this study was to test if the air-conditioning unit has an effect on the temperature of the engine using the twin cam 16 valve Nissan engine at 5\% significance level, from the problem statement in Equations (1) and (2), it can be deduced that the:

$$
\begin{gathered}
H_{t 0}: D_{t}=0 \\
H_{t a}>0 ; \text { or } \mu_{t 1}<\mu_{t 2}
\end{gathered}
$$

where $\mu_{t 1}$ is the mean temperature before the $\mathrm{A} / \mathrm{C}$ is run and $\mu_{t 2}$ is the mean temperature after $\mathrm{A} / \mathrm{C}$ is run.

The hypothesis indicates that the test is one-tailed test of the greater type.

$H_{t 0}$ represents the null hypothesis. If this is found true, it would mean that the A/C system does not have any effect on the condition of an internal combustion engine.

$H_{t a}$ represents the alternative hypothesis. If this is found true, it would mean that the $\mathrm{A} / \mathrm{C}$ system increases the temperature of the condition of an internal combustion engine.

$D_{t}$ represents the difference between the temperatures before and after the $\mathrm{A} / \mathrm{C}$ system is run.

The t-statistics $\left(t_{T}\right)$ was first calculated using Equation (3) and the components of the equation were gotten from Equations (4) and (5). The pair t-test was used because of the related samples and small sample size in line with the literature [10]. The calculated value of $t$-statistics after estimated was compared to the critical value of $\mathrm{t}$-statistics at the degrees of freedom $(n-1)$ to ascertain if the $\mathrm{A} / \mathrm{C}$ system has an effect of increasing temperature of the internal combustion engine.

$$
\begin{gathered}
t_{T}=\frac{\bar{D}-0}{\sigma_{\text {diff }} / \sqrt{n}} \\
\bar{D}_{t}=\frac{\sum D_{t}}{n}
\end{gathered}
$$




$$
\left(\sigma_{\text {diff }}\right)^{2}=\frac{\sum D_{t}^{2}-\left(\bar{D}_{t}\right)^{2} \cdot n}{n-1}
$$

\subsection{Speed Research Hypothesis}

This was used to test if the air-conditioning unit has an effect on the speed of the engine using the twin cam 16 valve Nissan engine at $5 \%$ significance level, from the problem statement in Equations (6) and (7), it can be deduced that the:

$$
\begin{gathered}
H_{s 0}: D_{s}=0 \\
H_{s a}>0 ; \text { or } \mu_{s 1}<\mu_{s 2}
\end{gathered}
$$

where $\mu_{s 1}$ and $\mu_{s 2}$ are the mean speeds before and after the $\mathrm{A} / \mathrm{C}$ is run on the engine.

The hypothesis indicates that the test is a one-tailed test.

$H_{s 0}$ represents the null hypothesis for the speed. If this is found true, it would mean that the A/C system does not increase the speed of the internal combustion engine

$H_{s a}$ represents the alternative hypothesis. If this is found true, it would mean that the $\mathrm{A} / \mathrm{C}$ system increases the speed of the internal combustion engine.

$D_{s}$ represents the difference between the speeds before and after A/C system is run. The test statistics for the speed was also calculated in a similar way to the temperature as expressed in Equations (8) to (10)

$$
\begin{gathered}
t_{s}=\frac{\bar{D}_{s}-0}{\sigma_{\text {diff }} / \sqrt{n}} \\
\bar{D}_{s}=\frac{\sum D_{s}}{n} \\
\left(\sigma_{\text {diff }}\right)^{2}=\frac{\sum D_{t}^{2}-\left(\bar{D}_{s}\right)^{2} \cdot n}{n-1}
\end{gathered}
$$

\subsection{Regression Data Analysis}

The data analysis was carried out using the regression tool package on Microsoft Excel Data software. This was done to investigate effects of the A/C on the temperature and speed of the engine through a set of regression models in each case.

\section{Result and Discussion}

\subsection{Experimental Results}

The results presented in Table 1 show the temperature $\left({ }^{\circ} \mathrm{C}\right)$ and speed (rpm) measurements taken before and after use of vehicle air conditioning system at a regular time interval of 10 minutes (mins). Each measurement was taken three (3) times and the average value was recorded in each case. The total number of recorded readings were 20 . The reading was started from 10 mins and was gradually increased on every 10 mins and a reading is taken in each case, until the total time of 200 minutes is reached. 


\subsection{Analysis of the Effects of Air-Conditioning on Temperature and Speed of the Engine}

The data were generated by the paired t-test in data analysis solver on the Microsoft Excel software. The result of the temperature and speed statistics are shown in Table 2 and Table 3.

Table 1 . The speed and temperature measurements.

\begin{tabular}{|c|c|c|c|c|c|}
\hline \multirow{2}{*}{$\mathrm{S} / \mathrm{N}$} & \multirow{2}{*}{ Time (mins) } & \multicolumn{2}{|c|}{ Temperature $\left({ }^{\circ} \mathrm{C}\right)$} & \multicolumn{2}{|c|}{ Speed (rpm) } \\
\hline & & $\mathrm{T}_{1}$ & $\mathrm{~T}_{2}$ & $\mathrm{~N}_{1}$ & $\mathrm{~N}_{2}$ \\
\hline 1 & 10.00 & 133.50 & 213.00 & 1260.00 & 1004.00 \\
\hline 2 & 20.00 & 170.10 & 239.00 & 894.00 & 979.00 \\
\hline 3 & 30.00 & 218.00 & 275.00 & 809.00 & 940.50 \\
\hline 4 & 40.00 & 219.00 & 285.50 & 515.00 & 935.00 \\
\hline 5 & 50.00 & 261.25 & 316.50 & 379.50 & 927.53 \\
\hline 6 & 60.00 & 291.69 & 341.85 & 255.50 & 932.17 \\
\hline 7 & 70.00 & 322.13 & 367.20 & 167.50 & 946.56 \\
\hline 8 & 80.00 & 352.57 & 392.55 & 115.50 & 970.68 \\
\hline 9 & 90.00 & 383.01 & 417.90 & 99.50 & 1004.55 \\
\hline 10 & 100.00 & 413.45 & 443.25 & 119.50 & 1048.15 \\
\hline 11 & 110.00 & 443.89 & 468.60 & 175.50 & 1101.50 \\
\hline 12 & 120.00 & 474.33 & 493.95 & 267.50 & 1164.58 \\
\hline 13 & 130.00 & 504.77 & 519.30 & 395.50 & 1237.41 \\
\hline 14 & 140.00 & 535.21 & 544.65 & 559.50 & 1319.97 \\
\hline 15 & 150.00 & 565.65 & 570.00 & 759.50 & 1412.28 \\
\hline 16 & 160.00 & 596.09 & 595.35 & 995.50 & 1514.32 \\
\hline 17 & 170.00 & 626.53 & 620.70 & 1267.50 & 1626.11 \\
\hline 18 & 180.00 & 656.97 & 646.05 & 1575.50 & 1747.63 \\
\hline 19 & 190.00 & 687.41 & 671.40 & 1919.50 & 1878.90 \\
\hline 20 & 200.00 & 717.85 & 696.75 & 2299.50 & 2019.90 \\
\hline
\end{tabular}

Table 2. Temperature statistics.

\begin{tabular}{|c|c|c|}
\hline Parameters & $\mathrm{T}_{1}$ & $\mathrm{~T}_{2}$ \\
\hline Mean & 428.67 & 455.925 \\
\hline Variance & $32,456.37$ & $22,498.27$ \\
\hline Observations & 20 & 20 \\
\hline df & \multicolumn{2}{|c|}{19} \\
\hline t Stat & \multicolumn{2}{|c|}{-4.0329} \\
\hline $\mathrm{P}(\mathrm{T} \leq \mathrm{t})$ one-tail & \multicolumn{2}{|c|}{0.000355} \\
\hline t Critical one-tail & \multicolumn{2}{|c|}{1.729133} \\
\hline $\mathrm{P}(\mathrm{T} \leq \mathrm{t})$ two-tail & \multicolumn{2}{|c|}{0.000711} \\
\hline t Critical two-tail & \multicolumn{2}{|c|}{2.093024} \\
\hline
\end{tabular}


Table 3. Speed statistics.

\begin{tabular}{|c|c|c|}
\hline Parameters & $\mathrm{N}_{1}$ & $\mathrm{~N}_{2}$ \\
\hline Mean & 741.5 & 1235.535 \\
\hline Variance & $409,767.8$ & $121,517.5$ \\
\hline Observations & 20 & 20 \\
\hline $\mathrm{df}$ & \multicolumn{2}{|c|}{19} \\
\hline t Stat & \multicolumn{2}{|c|}{-5.51832} \\
\hline $\mathrm{P}(\mathrm{T} \leq \mathrm{t})$ one-tail & \multicolumn{2}{|c|}{$1.27 \mathrm{E}-05$} \\
\hline t Critical one-tail & \multicolumn{2}{|c|}{1.729133} \\
\hline $\mathrm{P}(\mathrm{T} \leq \mathrm{t})$ two-tail & \multicolumn{2}{|c|}{$2.53 \mathrm{E}-05$} \\
\hline t Critical two-tail & \multicolumn{2}{|c|}{2.093024} \\
\hline
\end{tabular}

\subsubsection{Temperature Analysis Interpretation}

As stated in Table 2, the calculated value of the t-statistics was given to be -4.0329 while the critical was $1.729133 . \mathrm{H}_{\mathrm{t} 0}$ is one-sided, the analysis has applied a one-tailed test (in the left tail because $\mathrm{H}_{\mathrm{t} 0}$ is of less than type, $\mu_{t 1}<\mu_{t 2}$ ) for determining the rejection region at 5 percent level of significance. Therefore, the critical value in Table 2 can be represented as $t-S t a t_{\text {critical }}<-1.73$. The observed value of $\mathrm{t}$ is $\approx-4.0329$ which falls in the rejection region and thus, we reject $\mathrm{H}_{\mathrm{t} 0}$ at 5 percent level and conclude that the $\mathrm{A} / \mathrm{C}$ has an effect of increasing the temperature of the engine over a meaningful period of hours.

\subsubsection{Speed Analysis Interpretation}

This was also stated in Table 3; the calculated value of the t-statistics is given to be -5.518 while the critical value was $1.729133 . \mathrm{H}_{\mathrm{s} 0}$ is one-sided and the analysis has applied a one-tailed test (in the left tail because $\mathrm{H}_{\mathrm{s} 0}$ is of less than type, $\mu_{s 1}<\mu_{s 2}$ ) for determining the rejection region at 5 percent level of significance. The critical value in Table 3 can be represented as $t-S_{\text {tat }}$ critical $<-1.73$ while the observed value of $t$ is $\approx-5.518$. This falls in the rejection region and thus, we reject $\mathrm{H}_{\mathrm{s} 0}$ at 5 percent level and conclude that the $\mathrm{A} / \mathrm{C}$ has an effect of increasing the speed of the engine over a significant number of hours

\subsection{Models of the Relationships between the Variables}

\subsubsection{Correlations among the Variables}

Multiple regression analyses were performed between the variables to determine their relationships. In the first instance, the analysis of the correlation between the temperature of the engine $\left(\mathrm{T}_{1}\right)$, before the $\mathrm{A} / \mathrm{C}$ is run; the temperature of the engine $\left(\mathrm{T}_{2}\right)$ after $\mathrm{A} / \mathrm{C}$ is run and the time is estimated. The second case was the analysis of the speed of the engine before $\left(\mathrm{N}_{1}\right)$ and after $\left(\mathrm{N}_{2}\right)$ A/C is run respectively. The correlation summaries among variables are shown in Table 4 and Table 5.

In the first case, from the result of the multiple correlation coefficient which has the value of 0.999992132 in Table 4, it was discovered that the correlation 
among the independent variables, $\mathrm{T}_{1}$ and time $(\mathrm{t})$ and a dependent variable, $\mathrm{T}_{2}$ is positive. Considering the second case, the value is 0.999653453 which also shows a similar relationship between the independent variables, $\mathrm{N}_{1}$ and time $(\mathrm{t})$, and dependent variable $\mathrm{N}_{2}$. The R-Square $\left(\mathrm{R}^{2}\right)$ is called the coefficient of determination; this value measures the percentage of variation in the dependent variable that can be explained by the independent variables. Using the values in Table 4 and Table 5, 99.9992132\% and $99.9307027 \%$ are the respective $\mathrm{R}^{2}$ values. The high percentage reveals accuracy of the proposed models is good at forecasting the independent variables in each of the two cases, i.e. $\mathrm{T}_{2}$ and $\mathrm{N}_{2}$. The standard error of regression is an appraisal of the fluctuations in each of the dependent variables about the regression line.

\subsubsection{Modal Analysis and Equations}

The results of the regression models in each case include the independent variables that are statistically significant in explaining the variations in the final parameters of the engine considered, final temperature $\left(\mathrm{T}_{2}\right)$ and final speed $\left(\mathrm{N}_{2}\right)$ respectively. The values of these models were validated in each case by Regression P-Value statistics, which is the probability of observing a test statistic more extreme than what we observed. If the $\mathrm{p}$-value of each coefficient in the regression analysis is less than the value of significant level $(0.05 \%$ or $5 \%)$ then there would be the acceptability that the values of the independent variables can be used to predict the dependent variable or the dependent variable in each case varies in line with their respective independent variables. The Regression model outputs generated by the Microsoft Excel data Analysis are shown in Table 6 and Table 7. In each case, the estimated p-value was less than $0.05 \%$ or $5 \%$. Hence the models are correct in predicting the final temperature $\left(\mathrm{T}_{2}\right)$ and final speed $\left(\mathrm{N}_{2}\right)$ of the engine.

Table 4. Correlation summary between $\mathrm{T}_{1}, \mathrm{~T}_{2}$ and time ( $\mathrm{t}$ ).

\begin{tabular}{cc}
\hline & Regression Statistics \\
\hline Multiple R & 0.999996066 \\
R Square & 0.999992132 \\
Adjusted R Square & 0.999991206 \\
Standard Error & 0.444806048 \\
Observations & 20 \\
\hline
\end{tabular}

Table 5. Correlation summary between $\mathrm{N}_{1}, \mathrm{~N}_{2}$ and time (t).

\begin{tabular}{cc}
\hline & Regression Statistics \\
\hline Multiple R & 0.999653453 \\
R Square & 0.999307027 \\
Adjusted R Square & 0.9992255 \\
Standard Error & 9.701301718 \\
Observations & 20 \\
\hline
\end{tabular}


Table 6. Temperature regression model.

\begin{tabular}{cccc}
\hline Independent Variables & Coefficients & Standard Error & P-value \\
\hline Intercept & 135.64 & 2.21 & $2.12 \times 10^{-21}$ \\
Time (t) & 1.02 & 0.06 & $5.69 \times 10^{-22}$ \\
$\mathrm{~T}_{1}$ & 0.50 & 0.02 & $9.93 \times 10^{-22}$ \\
\hline
\end{tabular}

Table 7. Speed regression model.

\begin{tabular}{cccc}
\hline Independent Variables & Coefficients & Standard Error & P-value \\
\hline Intercept & 634.00 & 4.55 & $1.93 \times 10^{-27}$ \\
Time (t) & 3.82 & 0.04 & $5.78 \times 10^{-24}$ \\
$\mathrm{~N}_{1}$ & 0.27 & 0.00 & $5.62 \times 10^{-22}$ \\
\hline
\end{tabular}

The model equations generated from the analysis of the regression coefficients in Table 6 and Table 7 are presented in Equations (11) and (12) for the temperatures and speeds before and after $\mathrm{A} / \mathrm{C}$ is put to use respectively.

$$
\begin{array}{r}
T_{2}=135.640+1.025 t+0.496 T_{1} \\
N_{2}=634.005+3.824 t+0.270 N_{1}
\end{array}
$$

Figure 4 and Figure 5 show the relationship between the different variables considered against time $(t)$ in each case before and after A/C system was used. In Figure 4, it can be observed that the temperature $T_{2}$ increases with time which is an indication that the temperature of the engine is increased over the specific time of using the $\mathrm{A} / \mathrm{C}$ system. Also, between the ranges of $540^{\circ} \mathrm{C}$ to $570^{\circ} \mathrm{C}$, at around 170 minutes, what was observed is the intersection of $\mathrm{T}_{1}$ and $\mathrm{T}_{2}$, at this equilibrium point, it can be inferred that these two conditions of the engine temperature are the same. In Figure 5, at the initial conditions, the final speed of the engine, $\mathrm{N}_{2}$, was observed to be less than the initial speed $\left(\mathrm{N}_{1}\right)$. Later, the decline in the initial speed of the engine was observed while the $\mathrm{N}_{2}$ maintained. The increase in fuel consumption of the engine may be accounted for the speed requirement after the A/C system is put to use. The relationship between the $\mathrm{T}_{1}$ and $T_{2}$ according to Figure 6 is linear while that of the speeds in Figure 7 varies according to fuel consumption experienced in the engine during the usage of $\mathrm{AC}$ system.

Figure 6 and Figure 7 show the relationship between the temperatures $\left(T_{1}\right.$ and $\left.\mathrm{T}_{2}\right)$ and the speeds $\left(\mathrm{N}_{1}\right.$ and $\left.\mathrm{N}_{2}\right)$ before and after the AC system is being used.

\section{Conclusion}

Analyses have been carried out to investigate the temperature and speed of the engine before and after A/C usage; the paired t-test analysis, at 5\% significant level showed that the air-conditioning system has effect of increasing the temperature and speed of the twin cam 16-valve Nissan engine but the regression analyses predicted that the temperature and the speed of the engine could drop 


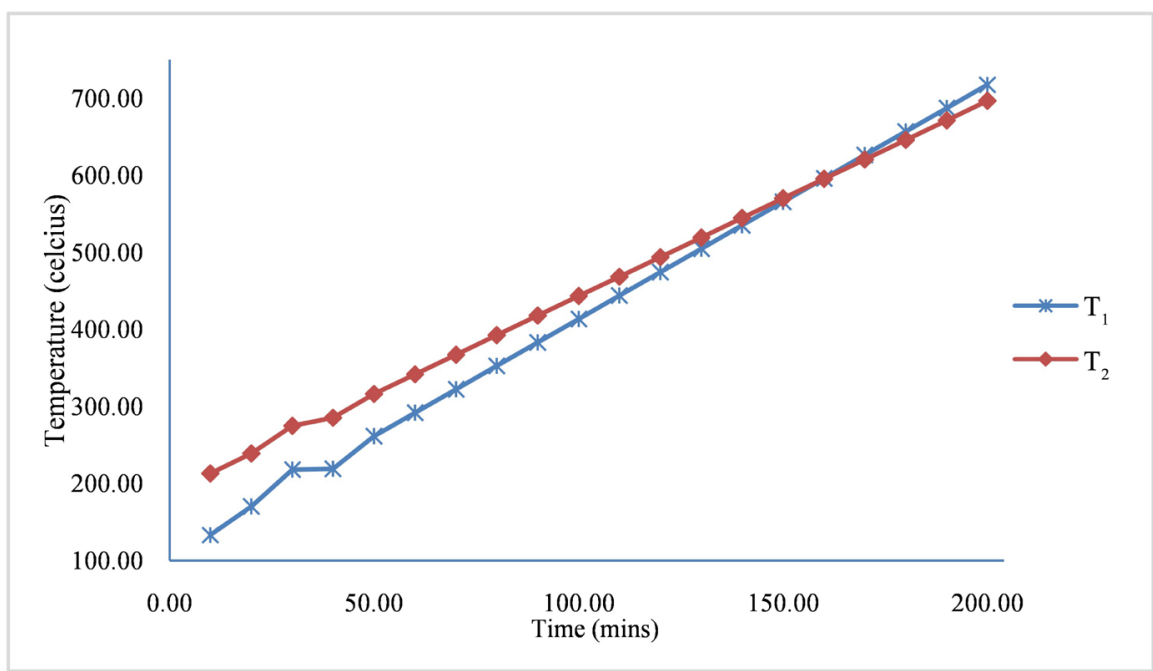

Figure 4. Plots of temperatures $\left(\mathrm{T}_{1}\right.$ and $\left.\mathrm{T}_{2}\right)$ against time $(\mathrm{t})$.

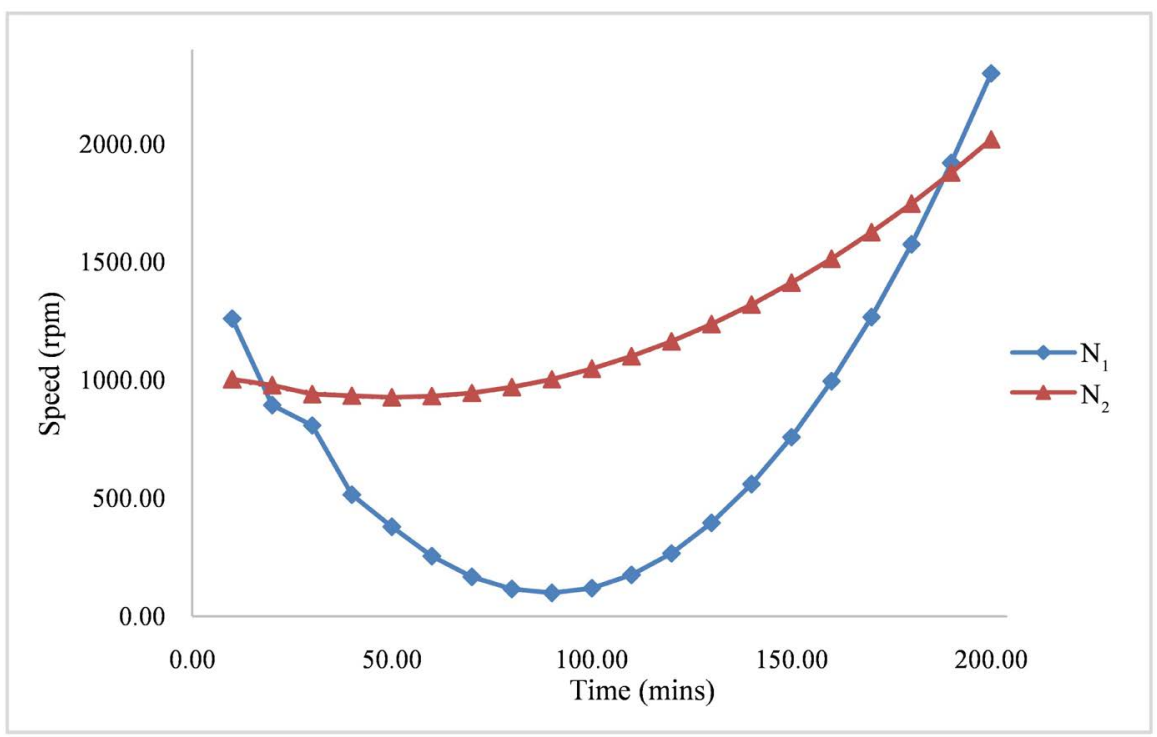

Figure 5. Plots of $\mathrm{N}_{1}$ and $\mathrm{N}_{2}$ against time (t).

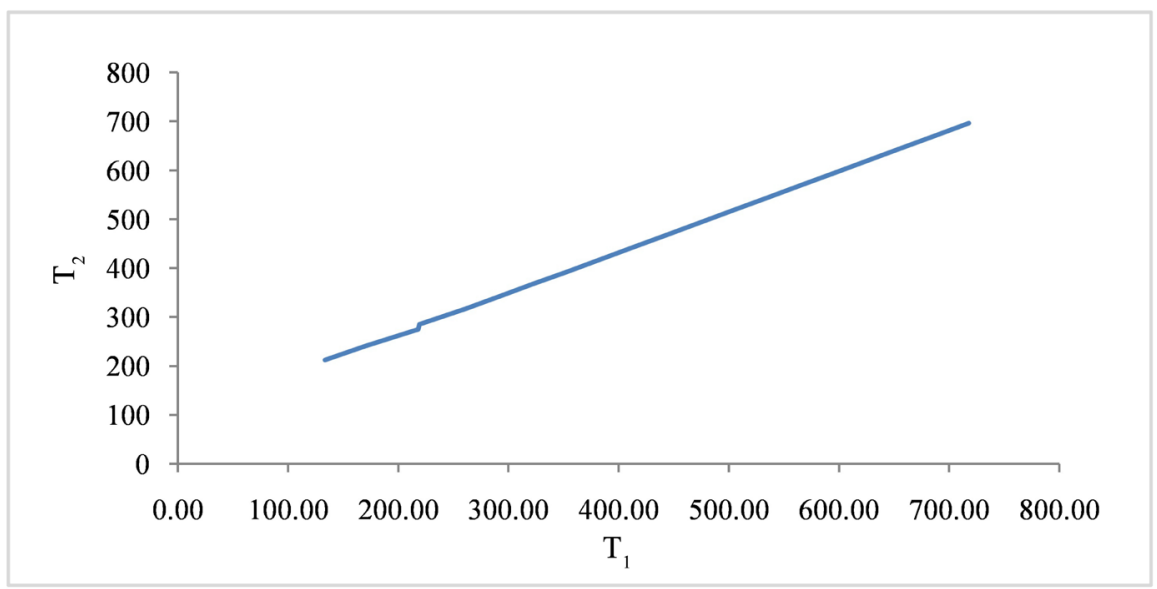

Figure 6. Relationship between $\mathrm{T}_{1}$ and $\mathrm{T}_{2}$. 


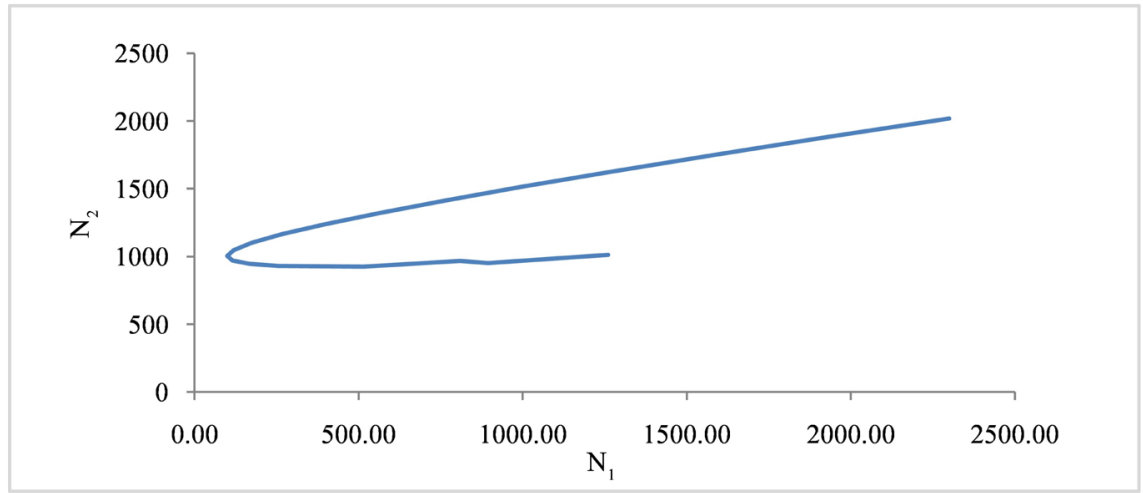

Figure 7. Relationship between $\mathrm{N}_{1}$ and $\mathrm{N}_{2}$.

over a significant amount of time even while air-conditioning is in usage. The correlation and R-Squared values showed that the data obtained had good correlations and the analysis is accurate in predicting the temperatures and speeds of the engine before and after air-conditioning system usage.

\section{Acknowledgements}

Authors hereby acknowledge the Head of Department of Mechanical Engineering of Federal University of Technology Akure, Nigeria; for the release of workshop tools and equipment required for this study.

\section{Conflicts of Interest}

The authors declare no conflicts of interest regarding the publication of this paper.

\section{References}

[1] Bhatti, M.S. (1999) Riding in Comfort Part II: Evolution of Automotive Air Conditioning. ASHRAE Journal, 41, 44-52.

[2] Kargilis, A. (2003) Design and Development of Automotive Air Conditioning Systems. ALKAR Engineering Company, 1-3.

[3] Daly, S. (2006) Automotive Air-Conditioning and Climate Control Systems. Elsevier Science \& Technology Books, 2-3.

[4] Rajput, R.K. (2007) Engineering Thermodynamic. 3rd Edition, Laxmi Publications, New Delhi and Boston, 713-777.

[5] Janotkova, E. and Pavelek, M. (2006) New Trends in the Field of Automobile Air Conditioning. Department of Thermomechanics and Environmental Engineering, Brno University of Technology, Brno, Czech Republic. https://doi.org/10.3320/1.2759084

[6] Kiatsiriroat, T. and Euakit, T. (1997) Performance Analyses of an Automotive Air Conditioning System with R22/R124/R152A Refrigerant. Applied Thermal Engineering, 17, 1085-1097. https://doi.org/10.1016/S1359-4311(97)80003-8

[7] Ratts, E.B. and Brown, J.S. (2000) An Experimental Analysis of Cycling in an Automotive Air Conditioning System. Applied Thermal Engineering, 20, 1039-1058. https://doi.org/10.1016/S1359-4311(99)00080-0 
[8] Wang, S.J. and Gu, J.J. (2004) Experimental Analysis of an Automotive Air Conditioning System with Two-Phase Flow Measurements. International Refrigeration and Air Conditioning Conference, Paper 735.

[9] Ariazone (2017) Automotive Air Conditioning Training Manual. http://www.ariazone.com

[10] Kothari, C.R. (2004) Research Methodology, Methods and Techniques. 2nd Edition, New Age International Publisher Limited, New Delhi, 184-229.

\section{Nomenclatures}

$\mathrm{A} / \mathrm{C}=$ Air-conditioning

$\mathrm{T}_{1}=$ Temperature $\left({ }^{\circ} \mathrm{C}\right)$ of the engine before Air Conditioning is put to use

$\mathrm{T}_{2}=$ Temperature $\left({ }^{\circ} \mathrm{C}\right)$ of the engine after Air Conditioning is put to use

$\mathrm{N}_{1}=$ Speed $(\mathrm{rpm})$ of the engine before Air Conditioning is put to use

$\mathrm{N}_{2}=$ Speed (rpm) of the engine after Air Conditioning is put to use

$\mathrm{t}=$ Time (minutes)

$\mathrm{H}_{\mathrm{t} 0}=$ Null hypothesis for the temperature

$\mathrm{H}_{\mathrm{s} 0}=$ Null hypothesis for the speed

$\mathrm{R}^{2}=$ Coefficient of determination

${ }^{\circ} \mathrm{C}=$ Degree Celsius

$\mathrm{RPM}=$ Revolution per minute

MW $=$ Mega Watts

$\mathrm{mm}=$ Millimetres

$\mathrm{RPM}=$ Revolutions per minute (speed) 